\title{
Lapatinib-loaded human serum albumin nanoparticles for the prevention and treatment of triple-negative breast cancer metastasis to the brain
}

\author{
Xu Wan ${ }^{1,2}$, Xiaoyao Zheng ${ }^{1}$, Xiaoyin Pang ${ }^{1}$, Zhiqing Pang ${ }^{1}$, Jingjing Zhao ${ }^{1}$, Zheming \\ Zhang $^{1}$, Tao Jiang ${ }^{3}$, Wei $\mathbf{X u}^{3}{ }^{3}$, Qizhi Zhang ${ }^{1}$, Xinguo Jiang ${ }^{1}$ \\ ${ }^{1}$ Department of Pharmaceutics, School of Pharmacy, Fudan University, Key Laboratory of Smart Drug Delivery, Ministry of \\ Education, Shanghai, People's Republic of China \\ ${ }^{2}$ Department of Pharmacy, South Campus, Renji Hospital, School of Medicine, Shanghai Jiaotong University, Shanghai, \\ People's Republic of China \\ ${ }^{3}$ Shanghai Zhangjiang Medicine Valley Public Service Platform Co., Ltd., Shanghai, People's Republic of China \\ Correspondence to: Qizhi Zhang, email: qzzhang@fudan.edu.cn
}

Keywords: brain metastasis, triple-negative breast cancer, lapatinib, human serum albumin nanoparticles, modified Nab technology

Received: October 27, 2015

Accepted: March 18, 2016

Published: April 12, 2016

\section{ABSTRACT}

Brain metastasis from triple-negative breast cancer (TNBC) has continued to lack effective clinical treatments until present. However, the feature of epidermal growth factor receptor (EGFR) frequently overexpressed in TNBC offers the opportunity to employ lapatinib, a dual-tyrosine kinase inhibitor of human epidermal growth factor receptor-2 (HER2) and EGFR, in the treatment of brain metastasis of TNBC. Unfortunately, the low oral bioavailability of lapatinib and drug efflux by blood-brain barrier have resulted in low drug delivery efficiency into the brain and limited therapeutic effects for patients with brain metastasis in clinical trials. To overcome such disadvantages, we developed lapatinib-loaded human serum albumin (HSA) nanoparticles, named LHNPs, by modified nanoparticle albumin-bound ( $\mathrm{Nab}$ ) technology. LHNPs had a coreshell structure and the new HSA/ phosphatidylcholine sheath made LHNPs stable in bloodstream. Compared to free lapatinib, LHNPs could inhibit the adhesion, migration and invasion ability of high brain-metastatic 4T1 cells more effectively in vitro. Tissue distribution following intravenous administration revealed that LHNPs (i.v., $10 \mathrm{mg} / \mathrm{kg}$ ) achieved increased delivery to the metastatic brain at 5.43 and 4.36 times the levels of Tykerb (p.o., $100 \mathrm{mg} / \mathrm{kg}$ ) and lapatinib solution (LS, i.v., $10 \mathrm{mg} / \mathrm{kg}$ ), respectively. Compared to the marketed Tykerb group, LHNPs had markedly better inhibition effects on brain micrometastasis and significantly extended the median survival time of 4T1 brain metastatic mice in consequence. The improved anti-tumor efficacy of LHNPs could be partly ascribed to down-regulating metastasis-related proteins. Therefore, these results clearly indicated that LHNPs could become a promising candidate for clinical applications against brain metastasis of TNBC.

\section{INTRODUCTION}

Breast cancer is the most common cancer in women, with more than 1.7 million new cases every year reported by the International Agency for Research on Cancer (IARC) [1]. Although the rapid development of surgical resection, radiotherapy and chemotherapies has successfully controlled the progression of primary breast tumors and prolonged the survival of patients, tumor metastasis has become a major cause of morbidity and mortality in patients with solid tumors. Breast cancer metastasizes primarily to the lung, liver and bones [2]. Brain metastasis represents a late relapse in patients, and the incidence of clinically evident brain metastasis among women with metastatic breast cancer accounts for $25 \%-34 \%$ [3].

Among all breast cancer subtypes, triple-negative breast cancer (TNBC) has the highest incidence of brain metastasis (up to $46 \%$ ) and the poorest prognosis [4]. The median survival time of TNBC patients with brain metastasis is less than 6 months. Characterized by the 
absence of the estrogen receptor (ER), the progesterone receptor (PR), and human epidermal growth factor receptor 2 (HER2) [5], both TNBC and its brain metastasis lack specific therapeutic targets. In addition, the blood-brain barrier (BBB) is a formidable obstacle to most potential chemotherapeutic drugs and macromolecule antibodies [6] that are clinically available for brain metastasis of TNBC. Therefore, no standard-of-care therapy has been recommended for patients with brain metastasis from TNBC until present.

In the past few years, many studies have proved that the epidermal growth factor receptor (EGFR) is frequently overexpressed in TNBC [7-9], in association with a high risk of brain metastasis. Accordingly, EGFR could potentially be used in diagnosis and molecular targeting therapy of this breast cancer subtype.

Lapatinib, a selective small-molecule dual-tyrosine kinase inhibitor of HER2 and EGFR, was approved in combination with capecitabine for use in HER2-positive patients with advanced metastatic breast cancer [10]. Its selective EGFR-targeting property suggests that lapatinib might be a candidate drug for brain metastasis from TNBC. Unfortunately, single-agent lapatinib for patients with brain metastasis achieved only $2.6 \%-6 \%$ partial responses [11]. The poor therapeutic effects might be attributed to the low bioavailability of the drug when administered as an oral tablet (Tykerb, unique commercial preparation of lapatinib, GlaxoSmithKline) [12] and to drug efflux by P-glycoprotein (P-gp) and breast cancer resistance protein (BCRP) [13, 14] existing at the $\mathrm{BBB}$, which limit the lapatinib delivery to the brain. Therefore, there is an urgent need for a new therapeutic strategy to enhance the brain delivery of lapatinib and to improve its efficacy against early brain metastasis.

Currently, nanoparticle-based drug delivery has been shown to avoid P-gp-mediated drug efflux, thus elevating drug bioavailability by systemic administration $[15,16]$. Moreover, nanoparticles can accumulate at the tumor site because of their enhanced permeability and retention (EPR). Among the existing macro-molecule biomaterials used for the preparation of nanoparticles, human serum albumin (HSA) offers obvious advantages. It is the most abundant plasma protein, with high stability during storage and in vivo, and it can be preferentially taken up by tumors $[17,18]$. In addition to the EPR effect, HSA nanoparticles can also bind to the $60-\mathrm{kDa}$ glycoprotein (gp60) receptor on vascular endothelial cells, subsequently facilitating the passage of nanoparticles across the endothelial barrier into the tumor. Furthermore, SPARC (secreted protein acidic and rich in cysteine), which is widely present in the extracellular matrix (ECM) of tumor tissue, can attract nanoparticles to inner tumor areas $[19,20]$, thus resulting in increased antitumor activity, such as Abraxane (paclitaxel-loaded HSA nanoparticles) [21]. In addition, lapatinib has a poor water solubility (only $7 \mu \mathrm{g} / \mathrm{mL}$ ) and high binding efficacy (>99\%) to albumin. Therefore, HSA nanoparticles could constitute a promising carrier for lapatinib.
Regarding this strategy, we constructed lapatinibloaded HSA nanoparticles (LHNPs) for treating TNBC brain metastasis. Phosphatidylcholine (PC), a safe material approved by FDA, was introduced into the nano-system to solubilize lapatinib and achieve the appropriate particle size. The possible interaction among the components of the nanoparticles was clarified using differential scanning calorimetry (DSC) analysis and the stability of LHNPs was evaluated in simulated human plasma. Since metastasis is an extremely complicated process involving local invasion, intravasation and extravasation of vascular system, growth at secondary site and angiogenesis [22, 23], adhesion assay, wound healing assay, migration and invasion assay and in vivo biodistribution were conducted. Finally, the antitumor efficacy of LHNPs in 4T1 brain metastatic mouse models was investigated, and its mechanisms of action were elucidated by biochemical index assays.

\section{RESULTS AND DISCUSSION}

\section{Characterization of nanoparticles}

Nab technology, a mature technology for nanoparticles industrialization, was modified to extend its range of application and prepare lapatinib-loaded HSA nanoparticles in this study. PC was introduced into the formulation due to the low solubility of lapatinib in chloroform $(1.18 \mathrm{mg} / \mathrm{mL})$. The nanoparticles presented spherical and uniform characteristics under transmission electronic microscopy (TEM), with a core-shell structure (Figure 1A). The mean particle size of the LHNPs was approximately $140 \mathrm{~nm}$ with a relatively narrow particle distribution (polydispersity index $=0.189$, Figure 1B) and the encapsulation efficiency was $84.9 \pm 2.45 \%$. LHNPs present positive zeta potential $(21.4 \pm 0.6 \mathrm{mV})$, which was primarily due to that the $\mathrm{pH}$ of water phase (4 6.5) was below the isoelectric point of $\mathrm{PC}(\mathrm{pH}$ 6.7).

\section{DSC analysis}

The possible interaction among lapatinib, $\mathrm{PC}$ and HSA can be detected by DSC experiments.

As shown in Figure 2, the physical mixture of lapatinib, HSA and PC displayed two peaks at approximately $105^{\circ} \mathrm{C}$ and $215^{\circ} \mathrm{C}$, which was quite similar to the HSA. Three endothermic peaks of PC appeared at about $40^{\circ} \mathrm{C}$, $168^{\circ} \mathrm{C}$ and $241^{\circ} \mathrm{C}$. No endothermic peaks was observed in DSC thermogram of LHNPs, indicating that lapatinib exist in amorphous state in nanoparticles. Combining the DSC results and transmission electron micrographs, the possible schematic figure for nanoparticles structure was depicted in Figure1C.

\section{In vitro stability}

It was reported that Abraxane was unstable after intravenous injection, and disassociate into individual 
albumin molecules in several seconds and then circulated in bloodstream as paclitaxel-albumin complexes without desired advantages of nanoparticles [24]. However, LHNPs exhibited strong stability in simulated human plasma at three concentrations similar to the plasma levels of lapatinib at different times after administration (Figure 3). No significant disassociation was observed when the lapatinib concentration was in the range of $10 \sim 100 \mu \mathrm{g} / \mathrm{mL}$ during $24 \mathrm{~h}$ incubation. When the lapatinib concentration was further decreased to $1 \mu \mathrm{g} / \mathrm{mL}$, LHNPs still remained stable for $2 \mathrm{~h}$ and became a little smaller after $4 \mathrm{~h}$. The significant stability difference between Abraxane and LHNPs could be attributed to the new structure of HSA/ PC sheath of LHNPs which enhanced the stability of LHNPs. These results suggested that LHNPs might circulate in bloodstream with integrate nanoparticle structure for hours after intravenous injection, which was essential for LHNPs to exhibit the advantages of EPR effects and protect lapatinib from the BBB efflux.

\section{Inhibition of metastasis in vitro}

While the exact mechanism of brain metastasis remains unclear, accumulated studies have proved that the brain metastatic process is a complex process involving multiple steps [25]. First, tumor cells escape from the primary tumor site by losing cell-cell adhesion and gaining motility, enabling them to invade the surrounding tissues [26]. Second, tumor cells degrade the extracellular matrix of the host organ using a variety of proteolytic enzymes [27], and then they move through the matrix and intravasate to enter the systemic circulation. Only a few circulating tumor cells can survive in the systemic circulation and be arrested in the brain by blood flow [28]. Finally, these metastasized cells manage to extravasate through the brain capillaries and embed themselves into the brain parenchyma to form metastasis [29]. To understand the underlying mechanisms and to assess the prevention capacity of LHNPs on brain metastasis, in vitro adhesion, migration and invasive assays were performed.

\section{Inhibition of adhesion ability}

We examined the influence of LS and LHNPs on the adhesion of 4T1 cells to the plates coated with Matrigel, which is basement member matrix. To avoid interference effects, the concentrations of LS and LHNPs were set at the level of $0.1 \mu \mathrm{g} / \mathrm{mL}$, which exerted no effects on cell viability as demonstrated in MTT assays [30]. As shown in Figure 4B, the inhibition effects of LS and LHNPs on cell adhesion were exerted in a time-dependent manner, and the LHNPs exhibited slightly stronger inhibitory effects than LS with increasing incubation time (LHNPs, $45.6 \%$ vs LS, $38.3 \%$ at $90 \mathrm{~min})$.

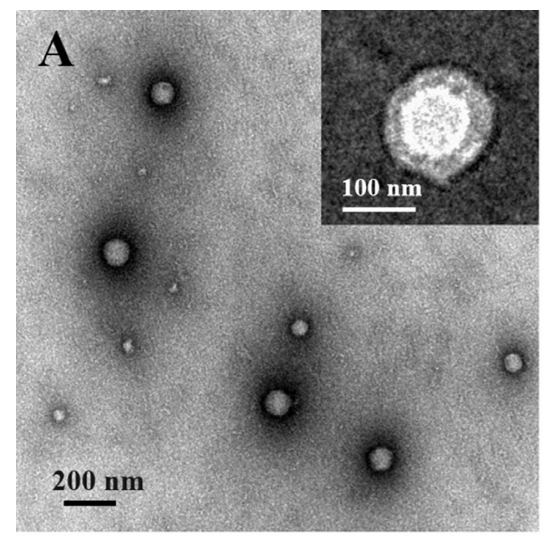

\section{B}

Size distribution intensity
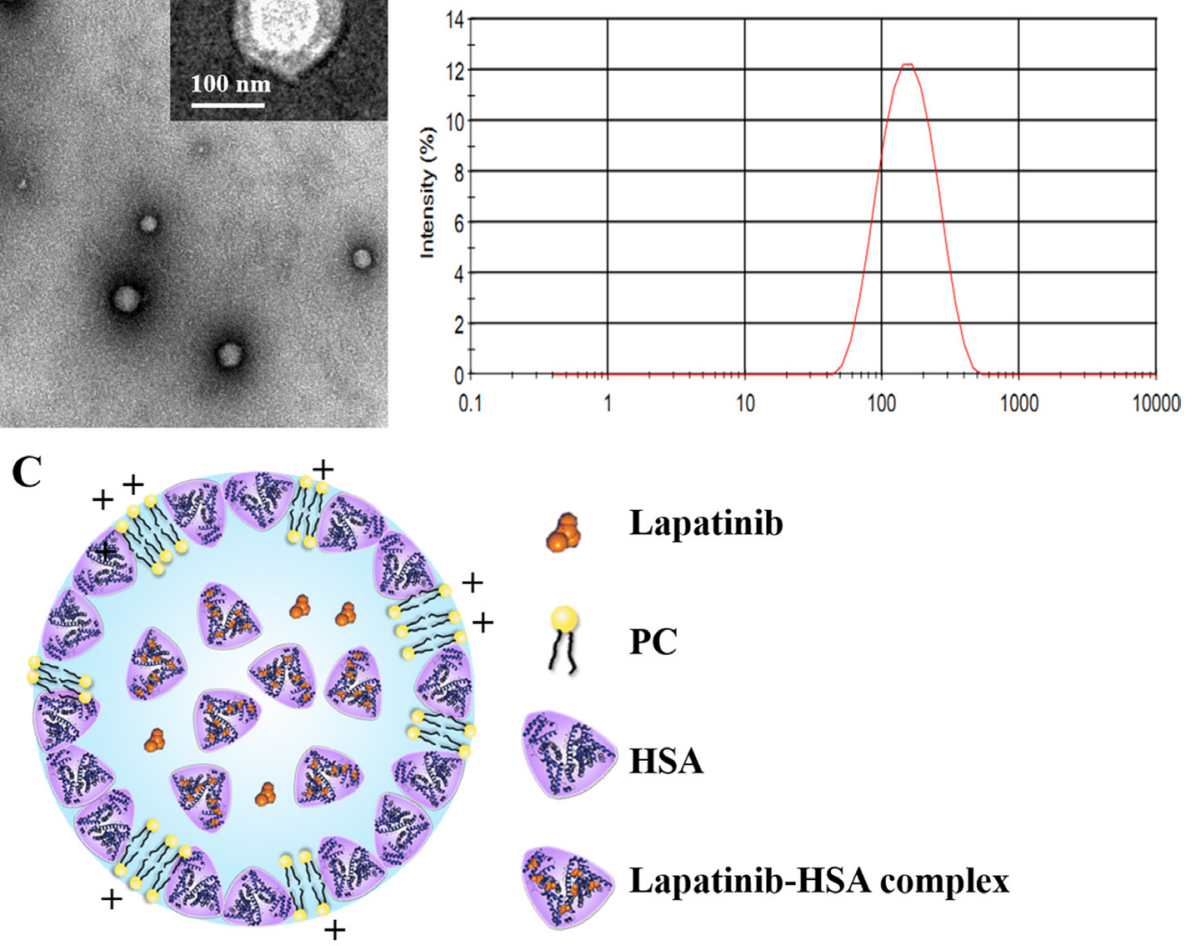

Figure 1: (A) Transmission electron micrographs of LHNPs stained with 2\% phosphotungstic acid solution or uranyl acetate. (B) A representative size distribution profile of LHNPs. (C) A schematic figure for LHNPs structure. 


\section{Inhibition of migration ability}

In addition to adhesion ability, the motility of tumor cells was also considered an important measurement for evaluating the metastatic potential of cells. Wound healing assay was used to investigate the lateral migration of cells, while transwell assay focused on the vertical mobility. As shown in Figure 4A, the cells in the control group exhibited strong wound healing ability, and they moved rapidly to the blank area of the scratch. After $24 \mathrm{~h}$, the wound healing rate was nearly
$100 \%$. In contrast, both LS and LHNPs significantly inhibited cell migration, with healing rates of $55 \%$ and $30 \%$, respectively. In transwell assays (Figure 5A, 5B), similar results were obtained. The cellular migration was inhibited to $28.0 \%$ by LS and to $18 \%$ by LHNPs compared to the control group at $24 \mathrm{~h}$ (Figure 5C).

All of these results demonstrated that LHNPs could more effectively inhibit the lateral and vertical mobility of 4T1 cells compared with free drug, which could form the basis for inhibition of the spontaneous metastasis of breast cancer in vivo.

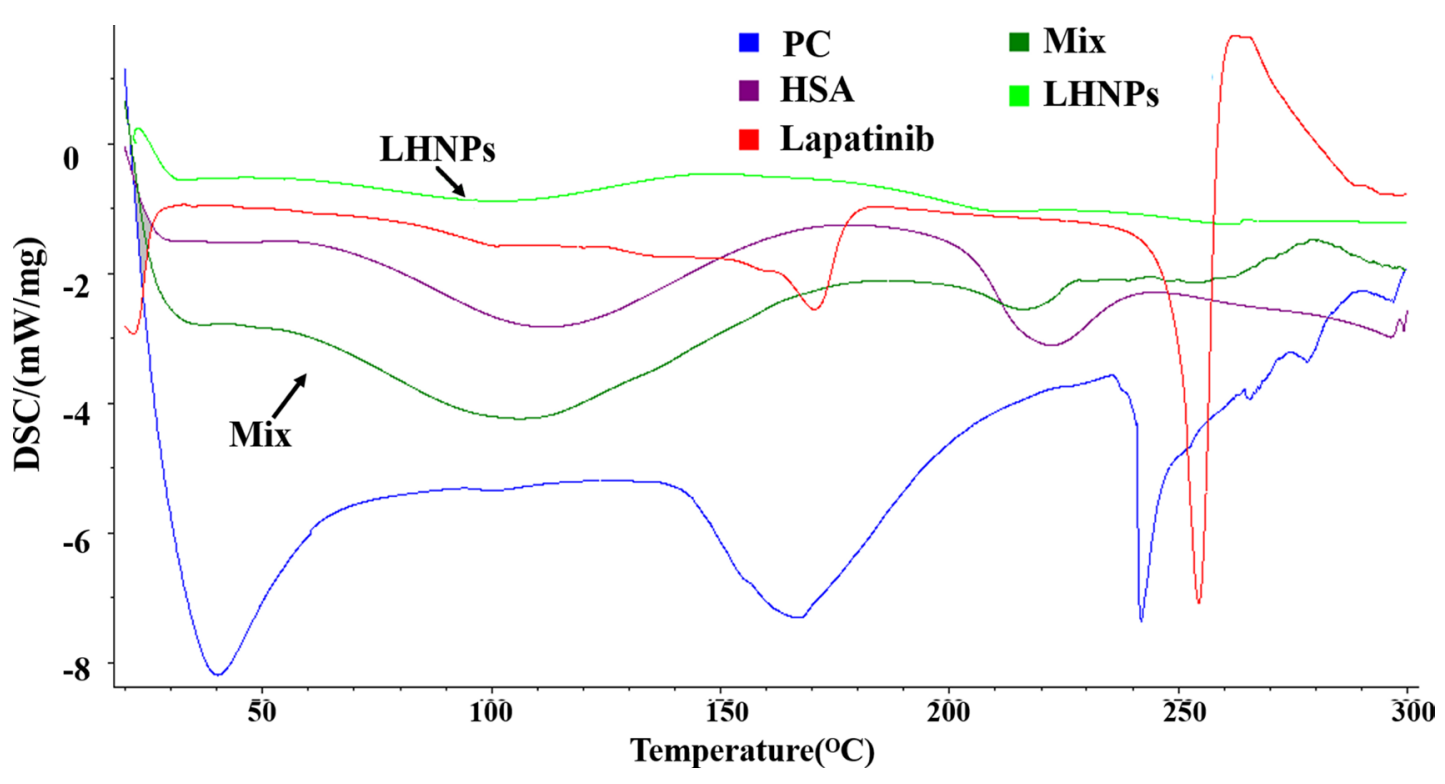

Figure 2: DSC patterns of lapatinib, HSA, PC, physical mixture of three components (Mix) and LHNPs.

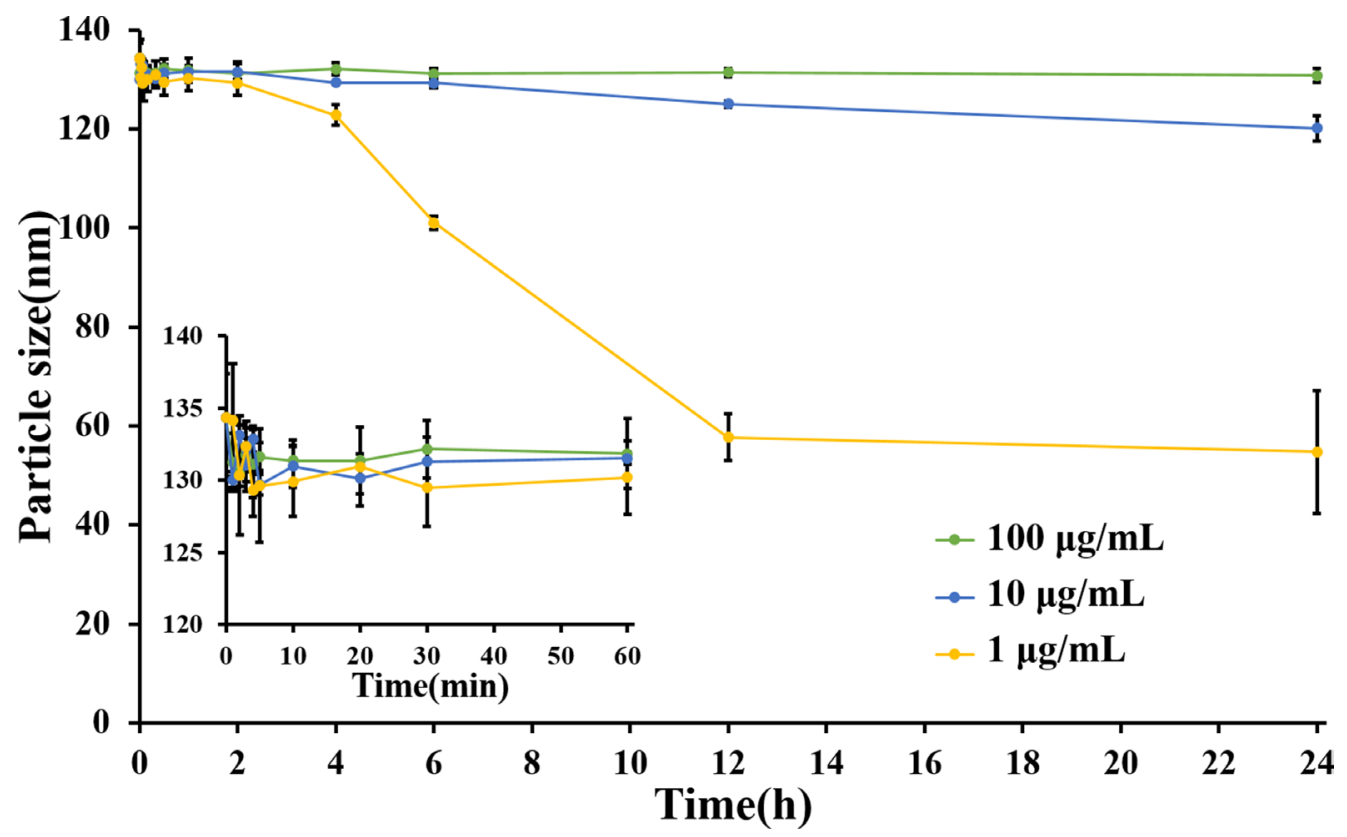

Figure 3: Changes of particle size of different concentrations of LHNPs in 5\% HSA medium, which simulated human plasma $(n=4)$. 


\section{Inhibition of invasion ability}

Invasive assay requires tumor cells to migrate through transwell filters precoated with Matrigel, a model of an extracellular matrix barrier. After enzymatically degrading that barrier, the tumor cells traversed the membrane and proliferated in a new location [31]. As shown in Figure 5D and 5E, the cells stained with crystal violet under the filters (invasive cells) were abundant in the view of the control group. However, the invasive cells were visibly decreased with LS and LHNPs treatment. Compared to LS, the inhibition effects of LHNPs were more obvious with the invasion rate decreasing from $38 \%$ to $15 \%$, demonstrating that LHNPs displayed significantly higher anti-metastatic ability (Figure 5F).

\section{In vivo model of brain metastasis}

Breast cancer cells have been reported to follow a hematogenous route for metastasis to the brain because there is barely a lymphatic system in the brain $[32,33]$. Therefore, 4T1-luc cells were injected into the right internal carotid arteries of female BALB/c mice to establish the in vivo model of brain metastasis [34,35]. The method was modified including ligation of external carotid artery, which could greatly prevent the injected tumor cells from
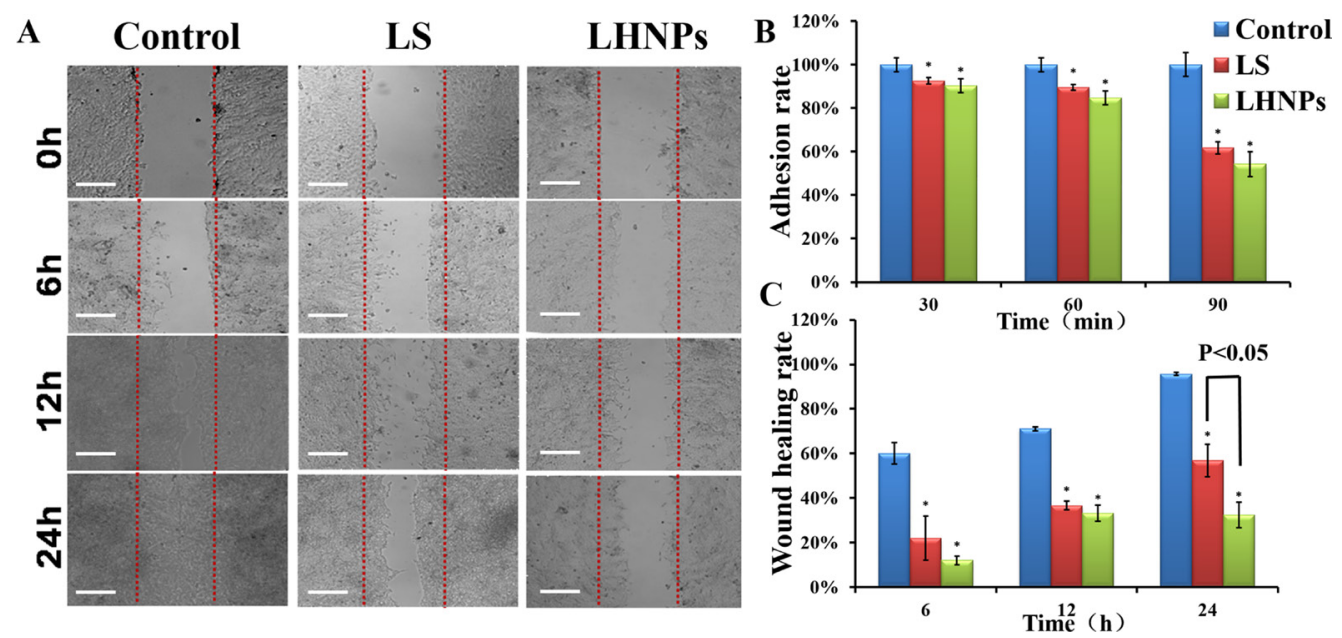

Figure 4: (A) Wound healing images after scratch incubation with drug-free medium, LS or LHNPs for $24 \mathrm{~h}$. The bar is $100 \mu \mathrm{m}$. (B, C) Quantitative analysis of adhesion rate $(\mathrm{B})$ and wound healing rate $(\mathrm{C})$ with different treatments. ${ }^{*} p<0.05$, compared with controls.
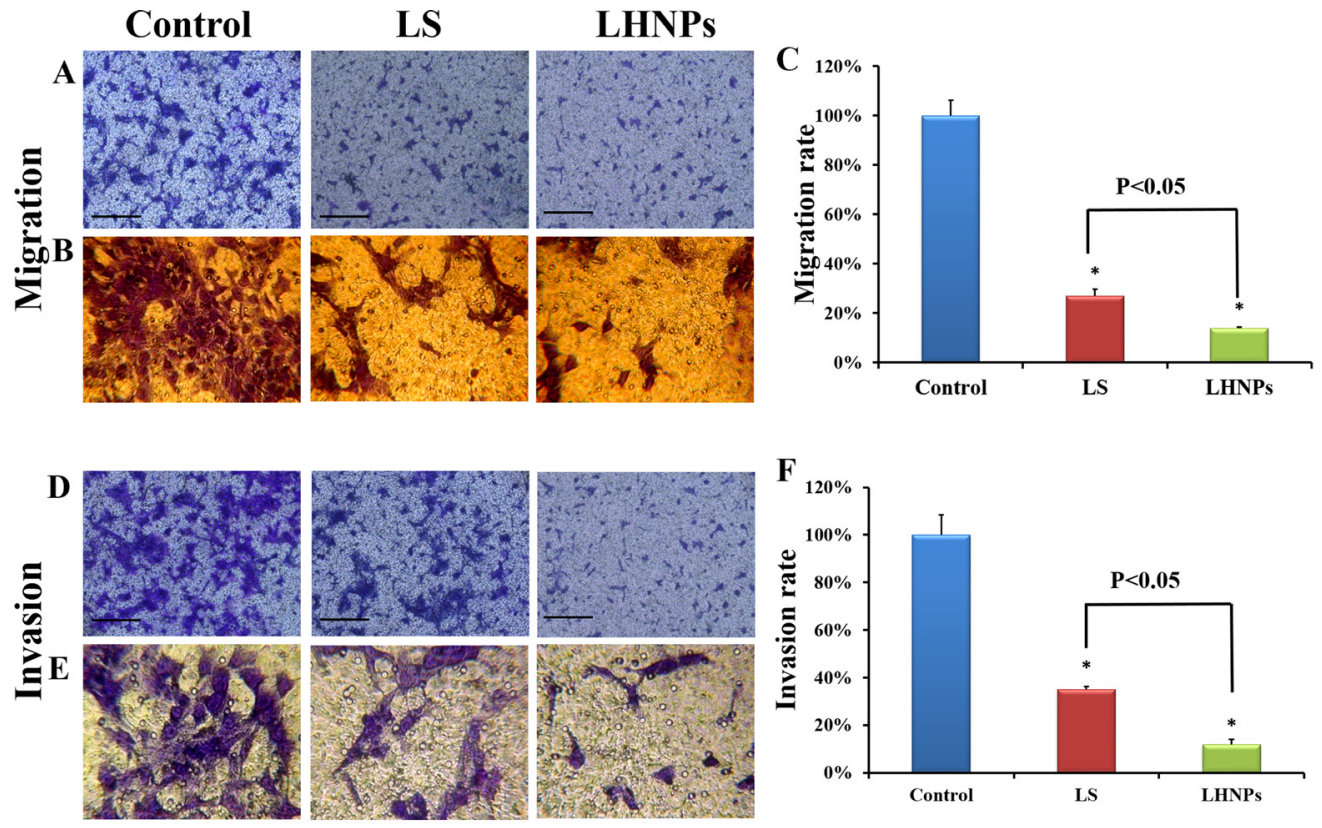

Figure 5: Effects of LS and LHNPs on cell migration and invasion in vitro. Representative fields of migrated and invasive cells stained by crystal violet after treatment with LS or LHNPs, compared to the control group under a fluorescent microscope (A, D) and an optical microscope $(\mathbf{B}, \mathbf{E} 400 \times)$. Quantitative analysis of the migration $(\mathbf{C})$ or invasion rate $(\mathbf{F})$ with different treatments. The scale bar represents $100 \mu \mathrm{m} .{ }^{*} p<0.05$, compared with the controls. 
colonizing on musculature on the head (supplied by the external carotid artery), and improve the success rate of model construction. As shown in Figure 6B, 4T1 cells with bioluminescence were found to localize in the brain after carotid artery injection and to produce persistent and increasing signals over time, indicating that the majority of the initially arrested cancer cells in the brain survived and displayed aggressively proliferative behaviors. In the PET/CT images in Figure 6C, the hypermetabolic signal in the brain (indicated by red arrows) shows the locations of metastasis and micrometastasis. From the intersecting surface of the brain, a major metastatic lesion with several scattered metastasis was seen in different parts of the brain. These results proved the success of building an in vivo model of brain metastasis.

\section{Tissue distribution in vivo}

To clarify the tumor-targeting efficacy of LHNPs, the distribution of drugs in normal tissues and in the brain lesions was detected after three formulations of lapatinib treatment. At the same time, to determine the integrity of the $\mathrm{BBB}$ in the brain metastasis animal models, the distribution of drugs in normal mice was used as a control. The dose determination of Tykerb and LHNPs was based on the oral dose of human and our pharmacokinetic study, both has similar AUC in plasma $\left(\mathrm{AUC}_{0-48 \mathrm{~h}} 125013.3 \pm 4475.3 \mathrm{mg} / \mathrm{L}\right.$ $\times \mathrm{h}$ vs $113718.2 \pm 2111.1 \mathrm{mg} / \mathrm{L} \times \mathrm{h}$ ) [30], suggesting the doses used to both groups are comparable.

In normal mice, the lapatinib concentrations in the brain in the LS group were quite low and could be negligible after $2 \mathrm{~h}$ post-injection (Figure 7), primary due to the drug-efflux effect. Lapatinib has been confirmed to be effluxed by P-gp and BCRP at the BBB [13, 14], thus restricting the entrance of free lapatinib into the brain to exert therapeutic effects. Nevertheless, markedly increased lapatinib concentrations in normal brains were found after LHNPs administration, and the brain AUC of LHNPs was 5.5-fold of that of LS (Table S1), indicating that HSA nanoparticle encapsulation could help to overcome BBB

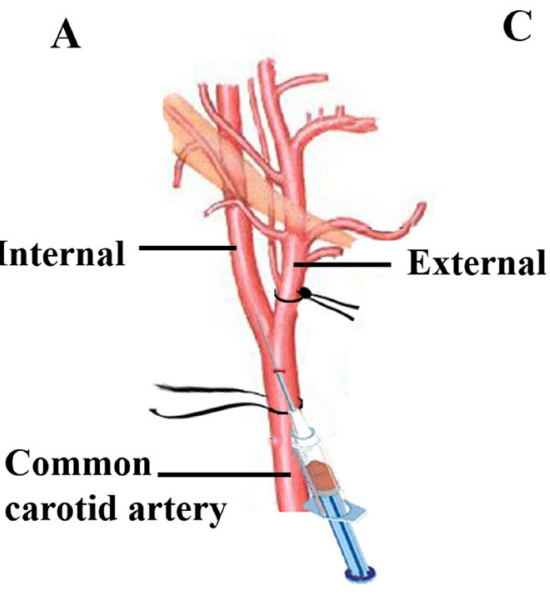

B
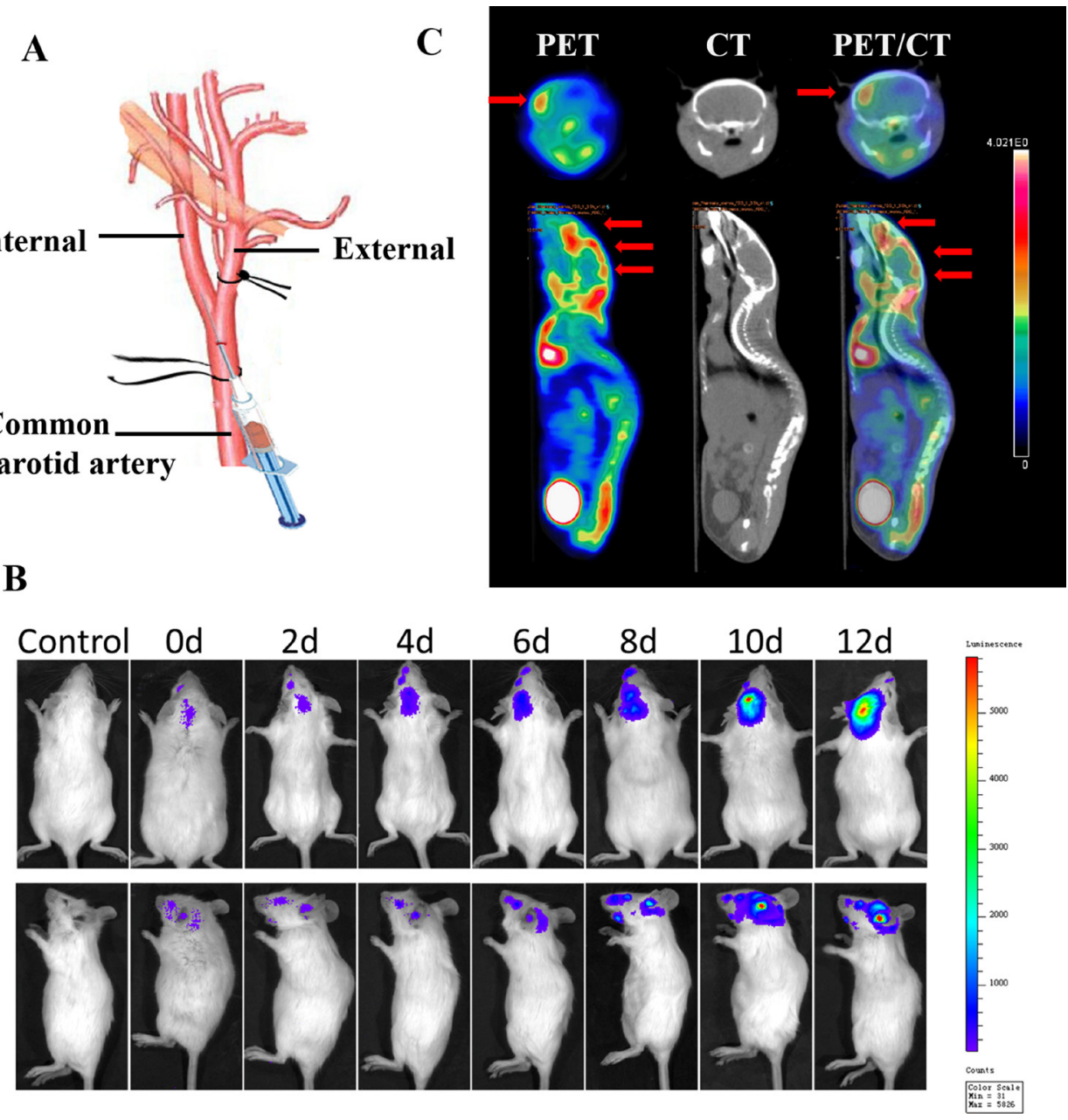

Figure 6: Establishment and confirmation of brain metastasis models. (A) Illustration of the technique for intracarotid injection of 4T1-luc cells. (B) Bioluminescence signal indicating brain colonization by 4T1 cells in a representative mouse at various times after injection of 4T1-luc cells. (C) Transverse and coronal sections of PET and CT images of a representative mouse with brain metastasis $4 \mathrm{~h}$ after tail-vein injection of ${ }^{18} \mathrm{~F}$-FDG. PET/CT fusion image confirms registration of hypermetabolic image on anatomic reference. 
efflux and efficiently deliver lapatinib across the BBB to the brain.

After being administered to the model mice with brain metastasis, LS displayed slightly increased accumulation in the brains, suggesting that the BBB became leaky, along with the progress of brain metastasis. Several researchers have demonstrated that the BBB is intact in and around brain metastases that are smaller than $0.25 \mathrm{~mm}$ in diameter, but larger metastasis can affect the integrity of the BBB [36]. This phenomenon was also observed in the LHNPs treatment group, with the drug concentrations in metastatic brains significantly higher than those in normal brains. Notably, lapatinib concentrations of LHNPs in the metastatic brains were the highest at all time points after administration, indicating the stronger penetration ability of LHNPs into the brain regardless of whether the BBB was intact or not. In contrast, Tykerb showed slow initial absorption, resulting in a gradual increase in concentration in all tissues. The lowest concentration was found in metastatic brains, in agreement with the weak therapeutic effects of Tykerb in patients with brain metastasis, as previously reported [11].

The lapatinib accumulations of LHNPs and LS in the brains with metastasis were 5.43 and 1.25 times the level of Tykerb, respectively. In addition, the ratio of $\mathrm{AUC}_{\text {brain }}$ to $\mathrm{AUC}_{\text {blood }}$ for $\operatorname{LHNPs}(0.144)$ was higher than that for $\mathrm{LS}(0.050)$ and Tykerb(0.019) after the effects of plasma concentration was excluded, indicating the great superiority of LHNPs at brain tumor targets in vivo, resulting from the advantages of EPR effect and HSA nanoparticles, as stated in the Introduction part.
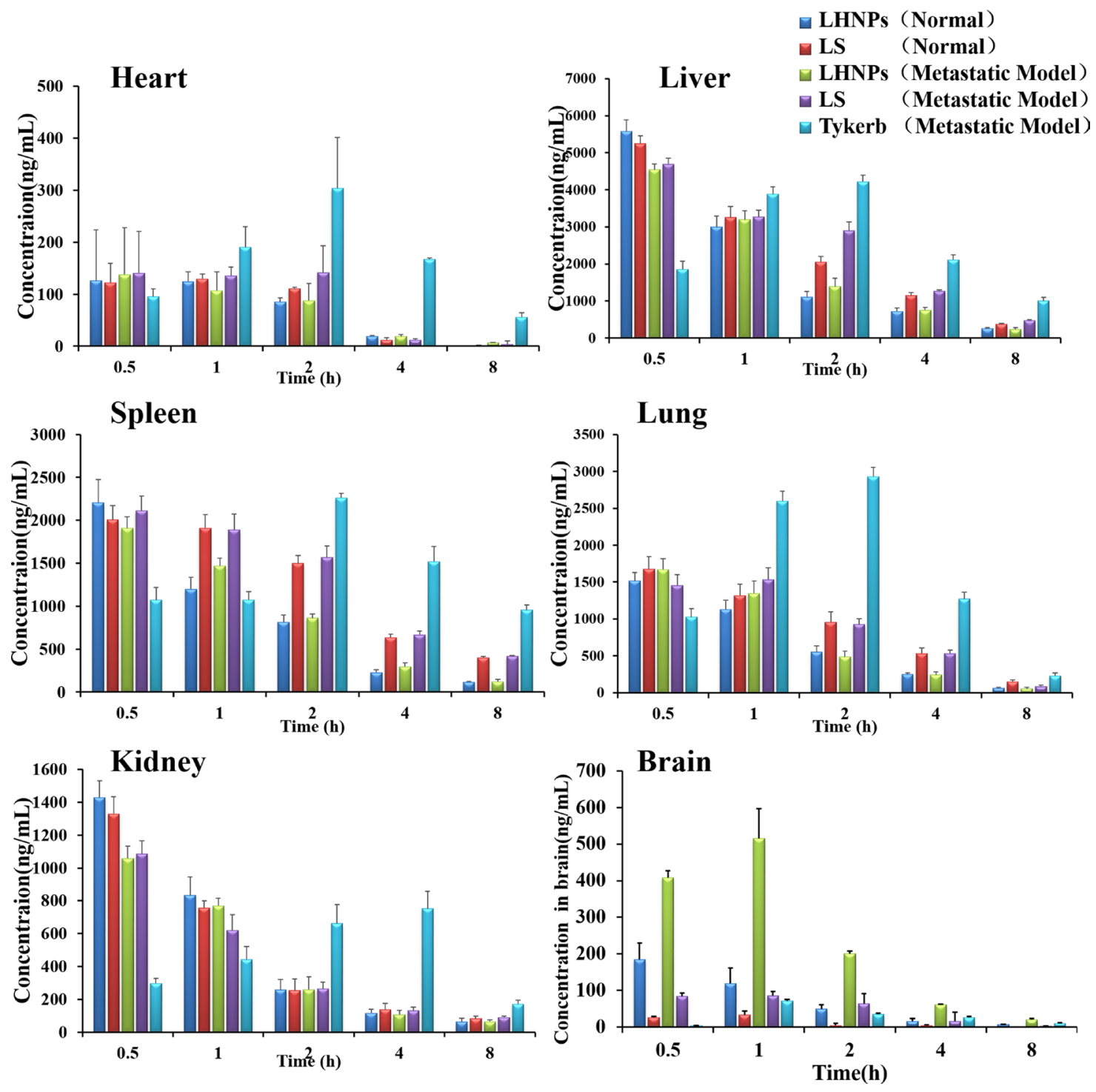

Figure 7: Tissue distribution of lapatinib in mice with brain metastasis at $0.5,1,2,4$, and $8 \mathrm{~h}$ after administration of Tykerb (p.0. $100 \mathrm{mg} / \mathrm{kg}$ ), LS (i.v. $10 \mathrm{mg} / \mathrm{kg}$ ) or LHNPs (i.v. $10 \mathrm{mg} / \mathrm{kg}$ ) and in normal mice after administration of LS and LHNPs $(n=4)$. 


\section{In vivo anti-tumor and anti-metastasis efficacy}

\section{Survival experiment}

Anti-tumor and anti-metastasis efficacy of LHNPs was evaluated by survival experiment performed on brain metastatic nude mice. As shown in Figure 8A, the Tykerb $(100 \mathrm{mg} / \mathrm{kg}), \mathrm{LS}(10 \mathrm{mg} / \mathrm{kg})$ and NPL $(3 \mathrm{mg} / \mathrm{kg})$ groups had weak inhibition effects on the bioluminescence signals in metastatic brains, compared with the strongest signals in the control group. However, LHNPs at a medium dose $(10 \mathrm{mg} / \mathrm{kg})$ or higher dose $(30 \mathrm{mg} / \mathrm{kg})$ not only suppressed tumor growth excellently, but they also efficiently inhibited the further transfer of the established metastasis to other brain regions (data not shown), exhibiting superior therapeutic effects on brain metastasis.

Consistent with the results of bioluminescence analysis, the median survival time of metastatic mice treated with LHNPs at medium and high doses (NPM: 29.6 days; NPH: 36.4 days) was significantly longer than those of mice treated with physiological saline (19.1 days, $p<0.05)$, Tykerb (22.6 days, $p<0.05)$, LS (23.0 days, $p<0.05$ ), and NPL (25.4 days, $p<0.05)$ (Figure 8B). Importantly, the total dose of NPH was approximately $10 \%$ that used for
Tykerb treatment, indicating that the application of LHNPs could reduce the dosage in clinical treatment, with fewer potential side effects compared with Tykerb.

\section{Histology}

At the end of the study, the metastatic brains were excised and imaged. Figure 9 shows that there was abundant brain micrometastasis (marked by yellow arrows) in the control group. Tykerb only slightly decreased the area of brain metastasis, while the number of metastatic lesions and area of total metastatic lesions were visibly decreased with LS or NPL treatment, indicating better inhibition of both injection formulations compared with oral Tykerb. In the groups receiving medium and high doses of LHNPs, fewer brain micrometastases were observed, demonstrating that LHNPs could effectively inhibit tumor metastasis in a dosedependent manner.

\section{Measurement of biochemical indexes}

Brain metastasis of breast cancer is a complex process involving multiple molecular mechanisms. MMP-2, a classical member of the MMP family, is vital in the
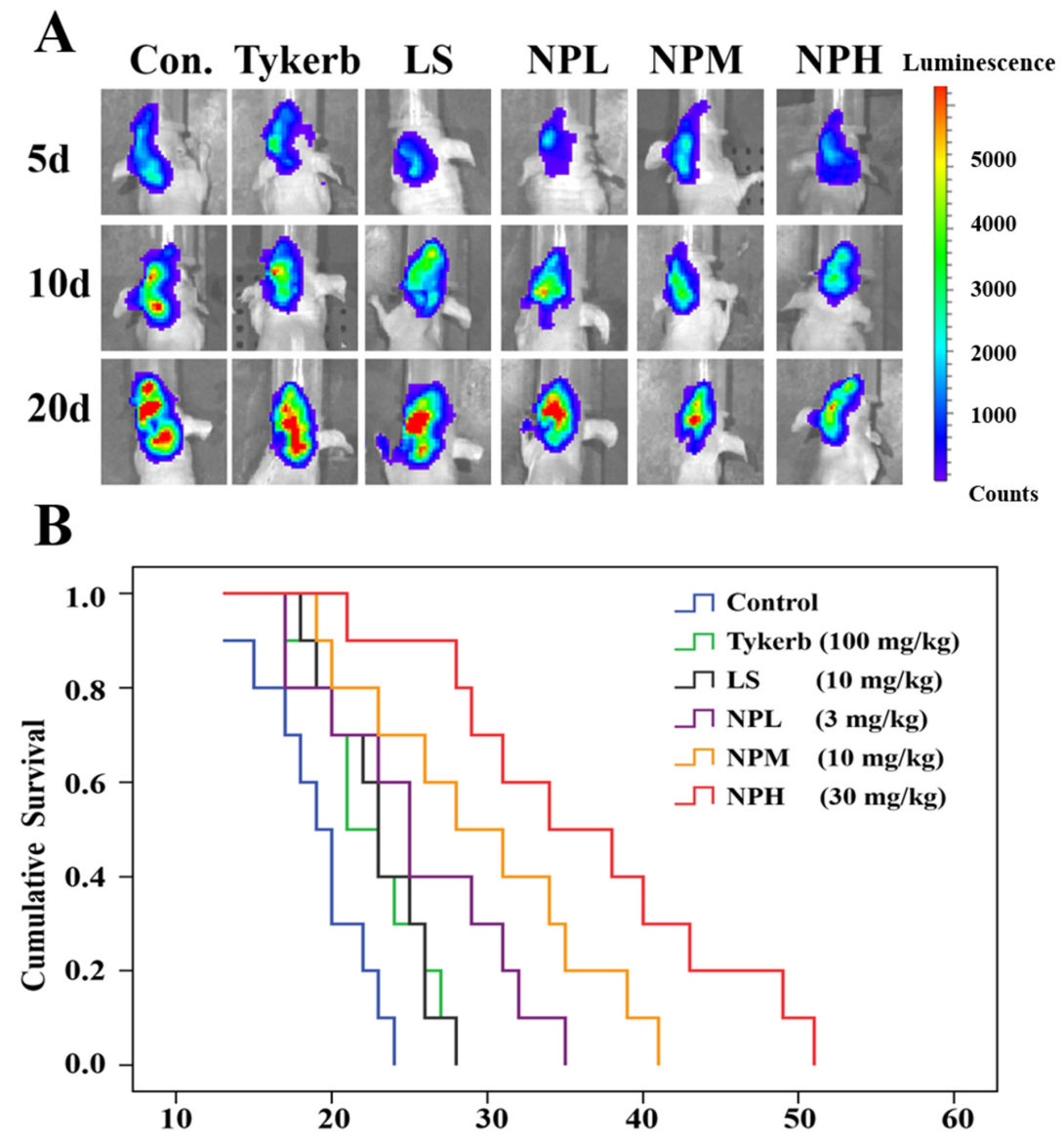

Figure 8: Anti-tumor and anti-metastasis effects of different treatments in 4T1 brain metastatic models. (A) Bioluminescence signals in metastatic brains of different treatments at 5, 10 and $20 \mathrm{~d}$. (B) Kaplan-Meier survival curves of mice with brain metastasis $(n=10)$. 
progression of intravasation by degrading the extracellular matrix and basement membrane [37]. uPA, a member of the serine protease family, is also involved in the cell-cell adhesion and degradation of the basement membrane by binding to its receptor (UPAR) [38], while OPN expression contributes to $4 \mathrm{~T} 1$ adhesion activities via mechanisms that are independent of uPA and MMPs [39]. Recently, some chemokines, such as stromal cell derived factor- $1 \alpha$ (SDF-1 $\alpha$ ) and its receptor CXCR4, were suggested to be involved in the progression of specific distant metastasis
[40, 41]. In particular, breast cancer cells expressing high levels of CXCR4 could increase their permeability through brain microvascular endothelial cells and facilitate their invasion into the brain [41]. To further explore the molecular mechanisms of LHNPs for brain metastasis, the expression levels of MMP-2, uPA, OPN, and CXCR4 in metastatic brains treated with three formulations were examined by western blotting analysis.

As shown in Figure 10, overexpression of these biochemical indices was obviously observed in the
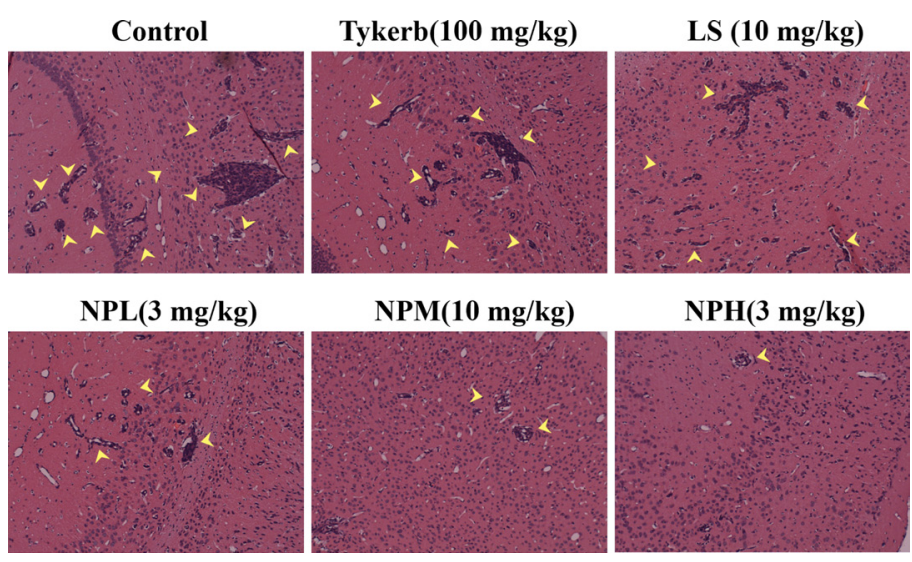

$\mathrm{NPH}(3 \mathrm{mg} / \mathrm{kg})$

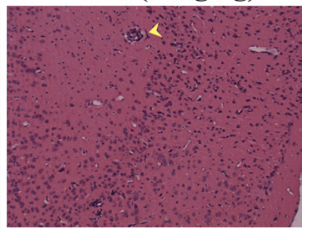

Figure 9: Representative images of $H \& E$ staining results of brains after different treatments.
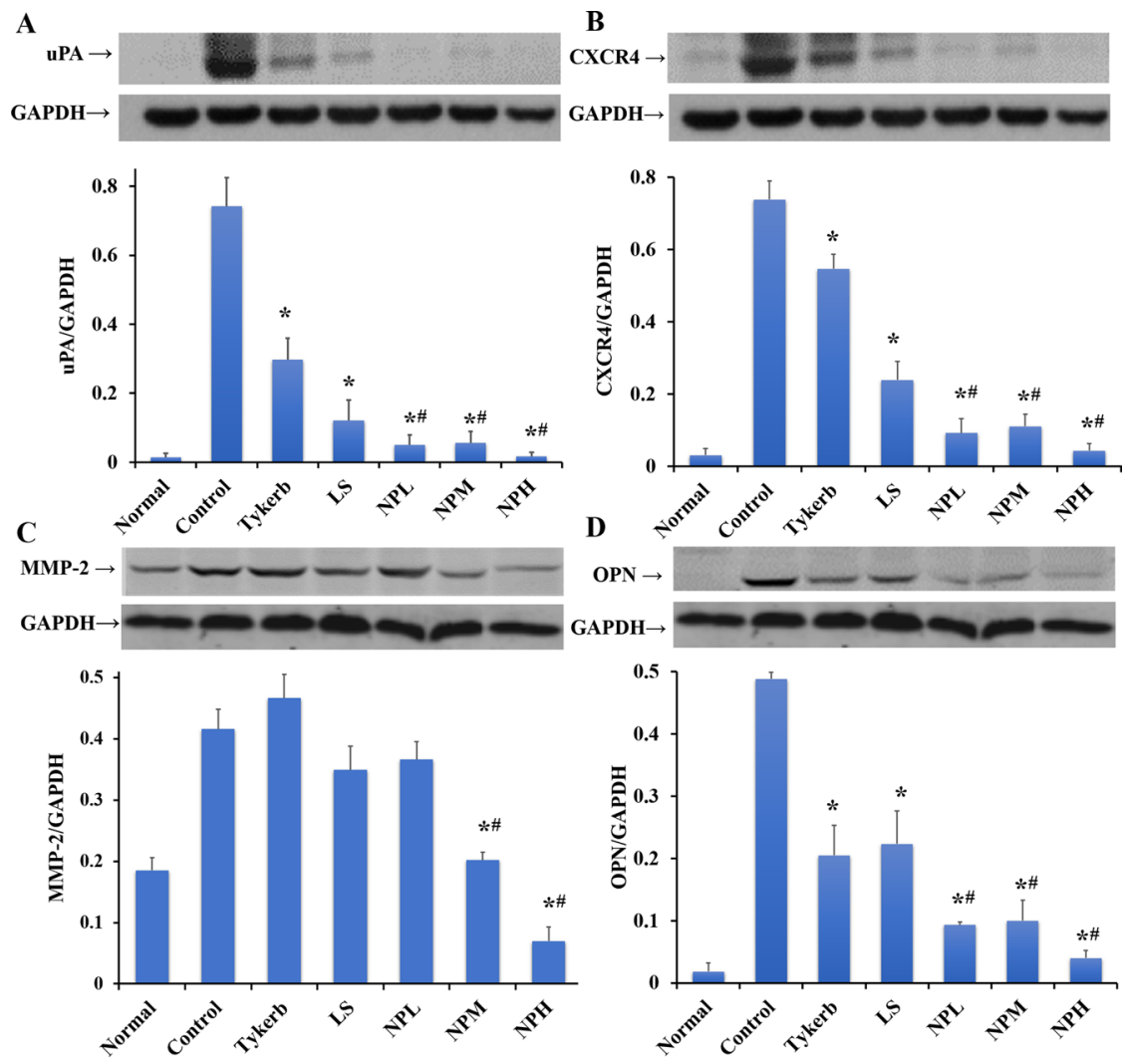

Figure 10: Western blotting of uPA (A), CXCR4 (B), MMP-2 (C) and OPN (D) relative to GAPDH in the brain. The data are shown as the means \pm S.E.M.s $(n=3) .{ }^{*} p<0.05$, significantly different from the control group. ${ }^{*} p<0.05$, significantly different from the Tykerb group. 
metastatic brains in the control groups, while the lowest expression appeared in the normal group. The large dosage of Tykerb partly down-regulated UPA, CXCR4 and OPN expression, while LS showed similar or stronger effects in down-regulating the levels of these three proteins, but both formulations had little influence on the overexpression of MMP-2, suggesting that Tykerb and LS might only inhibit the adhesion ability and extravasation of 4T1 cells to some extent. However, significantly better inhibition efficacy was achieved in the groups receiving three dosages of LHNPs, especially NPH group, with the expression levels of the four proteins were at almost the same level as in the normal group, indicating that the incorporation of lapatinib into HSA nanoparticles could enhance drug delivery to brain lesions and further maximize the inhibitive potential of lapatinib itself.

\section{MATERIALS AND METHODS}

\section{Materials and animals}

Lapatinib ditosylate and Gefitinib were purchased from Melonepharma (Dalian, China). Tykerb was purchased from GlaxoSmithKline. Phosphatidylcholine (PC) was purchased from Shanghai Advanced Vehicle Technology Pharmaceutical Ltd. (Shanghai, China). 3-(4,5-dimethyl2-thiazolyl)-2,5-diphenyltetra-zoplium bromide (MTT), coumarin-6 and Hoechst 33342 dye were purchased from Beyotime (Haimen, China). D-luciferin (potassium salt) was obtained from Gold Biotechnology (St. Louis, USA). The 4T1 cell line was obtained from the Chinese Academy of Sciences Cell Bank. The 4T1-luc cell line was kindly donated by the Shanghai Institute of Materia Medica (Shanghai, China). RMPI medium, fetal bovine serum (FBS) and trypsin-EDTA solutions were obtained from Gibco (CA, USA). All of the other chemicals were analytical or reagent grade.

Female nude Balb/c mice (18-20 g) and ICR mice (20-25 g) were obtained from Shanghai Sino-British Sippr/BK Lab Animal Ltd. (Shanghai, China) and were maintained at a constant temperature $\left(25 \pm 1^{\circ} \mathrm{C}\right)$. The animal studies were conducted in accordance with the protocols approved by institutional animal care and use committee (IACUC), school of pharmacy, Fudan University.

\section{Preparation and characterization of nanoparticles}

Lapatinib-loaded human serum albumin nanoparticles (LHNPs) were prepared using modified Nab technology. Lapatinib and phosphatidylcholine (PC), at a weight ratio of 1:4, were dissolved in chloroform and then were dripped into $0.6 \% \mathrm{w} / \mathrm{v}$ HSA aqueous solution $(\mathrm{pH} 4 \sim 6.5)$ under high speed stirring to form an oil-in-water $(\mathrm{o} / \mathrm{w})$ emulsion. The primary emulsion was further passed through a Micro fluidizer (Nano DeBEE, USA) 6-14 times at 100-170 $\mathrm{MPa}$. After evaporation by rotary vacuum, the nanoparticle suspension was filtered through filter membranes (Millipore, $220 \mathrm{~nm}$ pore diameter) and freeze-dried (Virtis Model Benchtop K, USA).

The particle sizes and zeta potential of the nanoparticles were determined using the Malvern Zetasizer (Malvern, nanoZS, UK), and the morphological examination was performed using transmission electron microscopy (TEOL2010, JEM). The encapsulation efficiency of the LHNPs was measured using High Performance Liquid Chromatography (HPLC) method.

\section{Differential scanning calorimetry (DSC)}

The possible interaction among the components of LHNPs was confirmed by DSC experiments. Approximately $5 \mathrm{mg}$ of the five samples (lapatinib, HSA, PC, LHNPs, and a physic mixture of lapatinib, HSA, and PC) was put in crimped aluminum pans and heated from 20 to $300^{\circ} \mathrm{C}$ at a rate of $10 \mathrm{~K} / \mathrm{min}$ under constant purging of nitrogen at $10 \mathrm{~mL} / \mathrm{min}$ using DSC 204/1/G, Phoenix (NetzschGeratebau, GmbH, Selb, Germany).

\section{In vitro stability studies}

A variety of ingredients in human bloodstream might induce the dissociation of HSA nanoparticles, thus leading to the reduction of particle size of nanoparticles [42]. Accordingly, the changes of particle size were used to evaluate the stability of LHNPs in bloodstream. An isotonic saline solution containing $5 \%(\mathrm{w} / \mathrm{v})$ human serum albumin, similar to the main compositions of human plasma, was served as the incubation medium. LHNPs were dispersed in the medium at final concentrations of 1,10 , and $100 \mu \mathrm{g} / \mathrm{mL}$, respectively, and then incubated at $37^{\circ} \mathrm{C}$. The particle size of LHNPs was determined at predetermined time points $(n=4)$ by the Malvern Zetasizer.

\section{Adhesion assay}

In order to better evaluate the efficacy of LHNPs in brain metastasis, 4T1, a highly metastatic murine breast cancer cell line, characterized as ER-/PR-/HER-2 negative and EGFR-expressing, was used to mimic human brain metastasis in this study $[43,44]$.

The effects of LHNPs on the adhesive ability of 4T1 cells were assayed as reported previously [45, 46] with slight modifications. Briefly, the 96-well plate was coated with Matrigel (BD Biosciences, Bedford, MA, USA) at a concentration of $10 \mathrm{mg} / \mathrm{L}$. Four hours later, adding $1 \%$ BSA in PBS for blocking non-specific sites. The 96well plate was balanced with culture medium for $15 \mathrm{~min}$. Then, untreated 4T1 cells and cells pretreated with LS and LHNPs (lapatinib concentration $0.1 \mu \mathrm{g} / \mathrm{mL}$ ) were seeded into precoated plate and were cultured for $90 \mathrm{~min}$. At the indicated time points, unattached cells were removed by washing three times with PBS, and the remaining cells (adherent cells) were numbered by colorimetric MTT assay. 


\section{Migration assays}

\section{Wound-healing assay}

The effects of LHNPs on cell lateral migration ability were assessed by wound-healing assay [47]. 4T1 cells were seeded into a 6-well plate and were cultured to $90 \%$ confluence in complete medium. The wounded lines were created by applying a plastic pipette tip $(1 \mathrm{~mm})$ to the cell monolayer across the center of each well. After rinsing with PBS three times to remove cell debris, the wounded monolayers were incubated in the cell culture medium with or without LS or LHNPs (the lapatinib concentration was $0.1 \mu \mathrm{g} / \mathrm{mL}$ ) for $24 \mathrm{~h}$. Images of cell migration into the wound surface were obtained under an inverted microscope at the indicated time points, and the wound healing rate was calculated as the ratio of wound width in the experimental group to that in the control group, using Image J software.

\section{Transwell migration assay}

Transwell migration assay was used to test the vertical movement of cells. A total of $5 \times 10^{5}$ cells in $100 \mu \mathrm{L}$ were plated in the top chamber of 24 -well transwell ( $8-\mu \mathrm{m}$ pore size, Corning, N.Y., USA). Before seeding, cells were plated in serum-free culture medium supplemented with $0.1 \%$ BSA and pre-incubated with LS or LHNPs (lapatinib concentration of $0.1 \mu \mathrm{g} / \mathrm{mL}$ ) for $24 \mathrm{~h}$, respectively. The lower chamber contained culture medium with $10 \%$ FBS, which served as a chemoattractant. After $24 \mathrm{~h}$ of incubation at $37^{\circ} \mathrm{C}$, the migrated cells remaining on the lower surface of the insert membranes were fixed and stained with crystal violet solution for $30 \mathrm{~min}$ at room temperature. After drying in the air, the migrated cells were photographed in five random fields, and quantified by absorbance at $570 \mathrm{~nm}$ in a plate reader after washing with $33 \%$ acetic acid, respectively.

\section{Invasion assay}

For cell invasion, the upper surfaces of transwell filters were precoated with Matrigel $(60 \mu \mathrm{L})$ as protocols for adhesion assay. Then, pretreated 4T1 cells $\left(2 \times 10^{6} / \mathrm{mL}\right)$ with LS or LHNPs (lapatinib concentration $0.1 \mu \mathrm{g} / \mathrm{mL}$ ) were suspended in $100 \mu \mathrm{L}$ of serum-free culture medium and were added to the tops of the Matrigel-coated transwell filters. Cells incubated without any treatment served as the controls. All of the cells were incubated at $37^{\circ} \mathrm{C}$ and were allowed to invade for $24 \mathrm{~h}$. After incubation, cells invaded through the transwell filters were fixed, stained and counted as per the protocols for migration assay.

\section{In vivo model of brain metastasis}

For in vivo imaging, $4 \mathrm{~T} 1$ cells were stably transfected with firefly luciferase (Luc) in a lentiviral construct.
Luc-tagged cancer cells (4T1-luc) were injected into the right internal carotid artery of female BALB/c mice, as per a protocol described previously $[30,31]$ with slight modifications. Briefly, the mice were anesthetized with chloral hydrate, and then the right common carotid artery of the mice was carefully exposed, separated from the vagal nerve and tied loosely with a surgical ligature (Figure 6A). The external carotid artery branch was also separated and was tied tightly with another surgical ligature. Then, 4T1luc cells $\left(2 \times 10^{7} / \mathrm{mL}\right)$ were suspended in PBS at a total volume of $100 \mu \mathrm{L}$ and were slowly injected into the internal carotid artery from the common carotid artery using a small syringe with a $32 \mathrm{G}$ needle (Becton Dickinson, Franklin Lakes, NJ). Subsequently, the ligature of the common carotid artery was pulled for hemostasis and was then removed before the wound was sealed.

The location and growth of brain metastasis were monitored by repeated noninvasive bioluminescence imaging, using an IVIS Spectrum Imaging System (Caliper) after luciferin injection (i.p. $0.15 \mathrm{~g} / \mathrm{kg}$,) on days $0,2,4,6$, 8,10 and 12 after cell injection. To confirm the successful establishment of brain metastasis models, in vivo PET/ CT was used for metastasis detection (Supplementary Information).

\section{Biodistribution studies}

To clarify the tumor-targeting efficacy of LHNPs, the concentration of lapatinib in different tissues was measured after administration. Sixty brain metastasis mice were randomly divided into three groups, receiving Tykerb (p.o., $100 \mathrm{mg} / \mathrm{kg}$ ), LS (i.v., $10 \mathrm{mg} / \mathrm{kg}$ ) or LHNPs (i.v., $10 \mathrm{mg} / \mathrm{kg}$ ). To determine the integrity of the BBB in brain metastasis animal models and the penetration ability of LHNPs across the $\mathrm{BBB}$ in vivo, 30 normal mice were also divided into two groups, receiving LS or LHNPs at same dose, and they served as control groups. Subsequently, the mice were sacrificed, and blood and tissues (heart, liver, spleen, lungs, kidneys and brain) were collected at $0.5,1,2,4$, and $8 \mathrm{~h}$ after drug administration.

Lapatinib concentrations in plasma and tissue samples were analyzed by LC/MS/MS [32]. Then the area under the blood or tissue concentration versus time curve $\left(\mathrm{AUC}_{0-\mathrm{-}}\right)$ was calculated using the trapezoidal method.

\section{Effects of the lapatinib formulations on brain metastasis model mice}

\section{In vivo inhibition of brain metastasis}

Nude brain metastasis mice were established as described above. After being examined under the IVIS Spectrum Imaging System (Caliper), mice with similar bioluminescence signals were randomly divided into six groups $(n=16)$. The mice were injected with NPH (LHNPs, $30 \mathrm{mg} / \mathrm{kg}$ ), NPM (LHNPs, $10 \mathrm{mg} / \mathrm{kg}$ ), NPL (LHNPs, $3 \mathrm{mg} / \mathrm{kg}$ ), LS $(10 \mathrm{mg} / \mathrm{kg}$ ) or saline (control 
group) via the tail vein at 3-day intervals. The compared group was orally administered Tykerb $(100 \mathrm{mg} / \mathrm{kg})$ every day. Bioluminescence signals were recorded at days 5, 10, 20 , and the inhibition efficacy of brain metastasis for each formulation was evaluated by measuring the survival time of the animals after the treatments.

\section{Histology}

On 20th day after treatment, three mice randomly selected from each group were sacrificed and fixed by heart perfusion with $4 \%$ paraformaldehyde solution, and their brains were harvested, fixed in 4\% paraformaldehyde, embedded in paraffin, and sectioned. The sections were stained with hematoxylin and eosin (H\&E) and were observed using an optical microscope.

\section{Measurement of biochemical indexes}

Animals ( $n=3$ for each group) were anesthetized and transcardially perfused with saline. The samples of brain metastasis were rapidly isolated and stored at $-80^{\circ} \mathrm{C}$. The expressions of urokinase-type plasminogen activator (uPA), osteopontin (OPN), matrix metalloproteinase-2 (MMP-2) and CXCR4 in the location with brain metastasis were determined using western blot analysis. The same location in the brains of normal mice was also analyzed as a negative group. The following antibodies were used: anti-urokinase-type plasminogen activator (uPA) (Santa Cruz Biotechnology, USA), anti-OPN (Abcam, USA), antimatrix metalloproteinase-2 (MMP-2, Epitomics, USA), and anti-CXCR4 (Abcam, USA).

\section{Statistical analysis}

All of the data are expressed as the mean \pm S.D. One-way ANOVA, followed by Dunnett's post hoc analysis, was used for multi-group comparison. Student's $t$-test was used for two-group comparison. Statistical significance was set at $p<0.05$.

\section{CONCLUSIONS}

In the present study, we prepared lapatinib-loaded HSA nanoparticles which have much possibility for clinical applications due to the safe adjuvants and mature Nabtechnology for industrialization. The in vitro experimental results demonstrated that LHNPs could remain the integrated structure of nanoparticles in bloodstream for hours and effectively inhibit the adhesion, migration and invasion ability of 4T1 cells. Following intravenous administration in 4T1 brain metastatic mice, LHNPs could remarkably increase lapatinib accumulation in metastatic brains and down-regulate metastasis-related proteins, which could be beneficial for blocking the metastasis process and reducing the occurrence of underlying distant metastasis. Additionally, increased drug delivery to the brain maximized the cytotoxic potential of lapatinib to cancer cells and exhibited excellent therapeutic effects in vivo. All of these results suggested that LHNPs might be a promising candidate for the prevention and treatment of brain metastasis of TNBC.

\section{ACKNOWLEDGMENTS AND FUNDING}

This work was supported by the National Basic Research Program of China (2013CB932500), the Special Project for Nano-technology from Shanghai (12nm0501500) and the National Natural Science Foundation of China (81472757).

\section{CONFLICTS OF INTEREST}

The authors declare that no competing financial interests exist.

\section{REFERENCES}

1. Ferlay J, Soerjomataram I, Dikshit R, Eser S, Mathers C, Rebelo M, Parkin DM, Forman D, Bray F. Cancer incidence and mortality worldwide: sources, methods and major patterns in GLOBOCAN 2012. Int J Cancer. 2015; 136:E359-E386.

2. Hess KR, Varadhachary GR, Taylor SH, Wei W, Raber MN, Lenzi R, Abbruzzese JL. Metastatic patterns in adenocarcinoma. Cancer. 2006; 106:1624-1633.

3. Bernard W. Stewart CPW. World cancer report 2014 ed.: World Health Organization, 2014.

4. Toft DJ, Cryns VL. Minireview: Basal-like breast cancer: from molecular profiles to targeted therapies. Mol Endocrinol. 2011; 25:199-211.

5. Bauer KR, Brown M, Cress RD, Parise CA, Caggiano V. Descriptive analysis of estrogen receptor (ER)-negative, progesterone receptor (PR)-negative, and HER2-negative invasive breast cancer, the so-called triple-negative phenotype: a population-based study from the California cancer Registry. Cancer. 2007; 109:1721-1728.

6. Robins HI, Liu G, Hayes L, Mehta M. Trastuzumab for breast cancer-related carcinomatous meningitis. Clin Breast Cancer. 2002; 2:316.

7. Nakajima H, Ishikawa Y, Furuya M, Sano T, Ohno Y, Horiguchi J, Oyama T. Protein expression, gene amplification, and mutational analysis of EGFR in triple-negative breast cancer. Breast Cancer. 2014; 21:66-74.

8. Gumuskaya B, Alper M, Hucumenoglu S, Altundag K, Uner A, Guler G. EGFR expression and gene copy number in triplenegative breast carcinoma. Cancer Genet Cytogenet. 2010; 203:222-229.

9. Reis-Filho JS, Pinheiro C, Lambros MB, MilaneziF, Carvalho S, Savage K, Simpson PT, Jones C, Swift S, Mackay A, Reis RM, Hornick JL, et al. EGFR amplification and lack of activating mutations in metaplastic breast carcinomas. J Pathol. 2006; 209:445-453. 
10. Tevaarwerk AJ, Kolesar JM. Lapatinib: a small-molecule inhibitor of epidermal growth factor receptor and human epidermal growth factor receptor- 2 tyrosine kinases used in the treatment of breast cancer. Clin Ther. 2009; 31:2332-2348.

11. Gril B, Palmieri D, Bronder JL, Herring JM, Vega-Valle E, Feigenbaum L, Liewehr DJ, Steinberg SM, Merino MJ, Rubin SD, Steeg PS. Effect of lapatinib on the outgrowth of metastatic breast cancer cells to the brain. J Natl Cancer Inst. 2008; 100:1092-1103.

12. Burris HR, Taylor CW, Jones SF, Koch KM, Versola MJ, Arya N, Fleming RA, Smith DA, Pandite L, Spector N, Wilding G. A phase I and pharmacokinetic study of oral lapatinib administered once or twice daily in patients with solid malignancies. Clin Cancer Res. 2009; 15:6702-6708.

13. Polli JW, Humphreys JE, Harmon KA, Castellino S, O’Mara MJ, Olson KL, John-Williams LS, Koch KM, Serabjit-Singh CJ. The role of efflux and uptake transporters in $[\mathrm{N}$ - $\{3$-chloro-4-[(3-fluorobenzyl)oxy]phenyl $\}-6-[5-$ (\{[2-(methylsulfonyl)ethyl]amino\}methyl)-2-furyl]-4quinazolinamine (GW572016, lapatinib) disposition and drug interactions. Drug Metab Dispos. 2008; 36:695-701.

14. Polli JW, Olson KL, Chism JP, John-Williams LS, Yeager RL, Woodard SM, Otto V, Castellino S, Demby VE. An unexpected synergist role of P-glycoprotein and breast cancer resistance protein on the central nervous system penetration of the tyrosine kinase inhibitor lapatinib (N-\{3-chloro-4-[(3fluorobenzyl)oxy]phenyl $\}-6-[5-(\{[2-($ methylsulfonyl)ethyl] amino \}methyl)-2-furyl]-4-quinazolinamine; GW572016). Drug Metab Dispos. 2009; 37:439-442.

15. Xie X, Tao Q, Zou Y, Zhang F, Guo M, Wang Y, Wang H, Zhou Q, Yu S. PLGA nanoparticles improve the oral bioavailability of curcumin in rats: characterizations and mechanisms. J Agric Food Chem. 2011, 59:9280-9289.

16. Gao H, Wang Y, Chen C, Chen J, Wei Y, Cao S, Jiang X. Incorporation of lapatinib into core-shell nanoparticles improves both the solubility and anti-glioma effects of the drug. Int J Pharm. 2014; 461:478-488.

17. Kratz F. Albumin as a drug carrier: design of prodrugs, drug conjugates and nanoparticles. J Control Release. 2008; 132:171-183.

18. Gao H, Cao S, Chen C, Cao S, Yang Z, Pang Z, Xi Z, Pan S, Zhang Q, Jiang X. Incorporation of lapatinib into lipoprotein-like nanoparticles with enhanced water solubility and anti-tumor effect in breast cancer. Nanomedicine (Lond). 2013; 8:1429-1442.

19. Elzoghby AO, Samy WM, Elgindy NA. Albumin-based nanoparticles as potential controlled release drug delivery systems. J Control Release. 2012; 157:168-182.

20. Gao H, Yang Z, Cao S, Xi Z, Zhang S, Pang Z, Jiang X. Behavior and anti-glioma effect of lapatinib-incorporated lipoprotein-like nanoparticles. Nanotechnology. 2012; 23:435101.

21. Desai N, Trieu V, Yao Z, Louie L, Ci S, Yang A, Tao C, De T, Beals B, Dykes D, Noker P, Yao R, et al. Increased antitumor activity, intratumor paclitaxel concentrations, and endothelial cell transport of cremophor-free, albumin-bound paclitaxel, ABI-007, compared with cremophor-based paclitaxel. Clin Cancer Res. 2006; 12:1317-1324.

22. Liotta LA, Steeg PS, Stetler-Stevenson WG. Cancer metastasis and angiogenesis: an imbalance of positive and negative regulation. Cell. 1991, 64:327-336.

23. Ellis LM, Fidler IJ. Angiogenesis and breast cancer metastasis. Lancet. 1995, 346:388-390.

24. Abraxis BioScience I: Abraxane ${ }^{\circledR}$-For the adjuvant treatment of node-positive breast cancer administered sequentially to standard doxorubicin-containing combination chemotherapy. Oncologic Drugs Advisory Committee Meeting. 2006:5.

25. Burnett RM, Craven KE, Krishnamurthy P, Goswami CP, Badve S, Crooks P, Mathews WP, Bhat-Nakshatri P, Nakshatri H. Organ-specific adaptive signaling pathway activation in metastatic breast cancer cells. Oncotarget. 2015; 6:12682-12696. doi: 10.18632/oncotarget.3707.

26. Cole P, Rodu B. Declining cancer mortality in the United States. Cancer. 1996; 78:2045-2048.

27. Bernards R. Cancer: cues for migration. Nature. 2003; 425:247-248.

28. Delattre JY, Krol G, Thaler HT, Posner JB. Distribution of brain metastases. Arch Neurol. 1988; 45:741-744.

29. Ito S, Nakanishi H, Ikehara Y, Kato T, Kasai Y, Ito K, Akiyama S, Nakao A, Tatematsu M. Real-time observation of micrometastasis formation in the living mouse liver using a green fluorescent protein gene-tagged rat tongue carcinoma cell line. Int J Cancer. 2001; 93:212-217.

30. Wan X, Zheng X, Pang X, Zhang Z, Jing T, Xu W, Zhang QZ. The potential use of lapatinib-loaded human serum albumin nanoparticles in the treatment of triplenegative breast cancer. Int J Pharm. 2015; 484:16-28.

31. Wolf K, Wu YI, Liu Y, Geiger J, Tam E, Overall C, Stack MS, Friedl P. Multi-step pericellular proteolysis controls the transition from individual to collective cancer cell invasion. Nat Cell Biol. 2007; 9:893-904.

32. Carbonell WS, Ansorge O, Sibson N, Muschel R. The vascular basement membrane as "soil" in brain metastasis. PLoS One. 2009; 4:e5857.

33. Tsukada Y, Fouad A, Pickren JW, Lane WW. Central nervous system metastasis from breast carcinoma. Autopsy study. Cancer. 1983; 52:2349-2354.

34. Myklebust AT, Helseth A, Breistol K, Hall WA, Fodstad O. Nude rat models for human tumor metastasis to CNS. Procedures for intracarotid delivery of cancer cells and drugs. J Neurooncol. 1994; 21:215-224.

35. Lorger M, Felding-Habermann B. Capturing changes in the brain microenvironment during initial steps of breast cancer brain metastasis. Am J Pathol. 2010; 176:2958-2971.

36. Fidler IJ, Balasubramanian K, Lin Q, Kim SW, Kim SJ. The brain microenvironment and cancer metastasis. Mol Cells. 2010; 30:93-98. 
37. Duffy MJ, Maguire TM, Hill A, McDermott E, O'Higgins N. Metalloproteinases: role in breast carcinogenesis, invasion and metastasis. Breast Cancer Res. 2000; 2:252-257.

38. Dass K, Ahmad A, Azmi AS, Sarkar SH, Sarkar FH. Evolving role of uPA/uPAR system in human cancers. Cancer Treat Rev. 2008; 34:122-136.

39. Mi Z, Guo H, Wai PY, Gao C, Kuo PC. Integrin-linked kinase regulates osteopontin- dependent MMP-2 and uPA expression to convey metastatic function in murine mammary epithelial cancer cells. Carcinogenesis. 2006; 27:1134-1145.

40. Barbero S, Bajetto A, Bonavia R, Porcile C, Piccioli P, Pirani P, Ravetti JL, Zona G, Spaziante R, Florio T, Schettini G. Expression of the chemokine receptor CXCR4 and its ligand stromal cell-derived factor 1 in human brain tumors and their involvement in glial proliferation in vitro. Ann N Y Acad Sci. 2002; 973:60-69.

41. Barbero S, Bajetto A, Bonavia R, Porcile C, Piccioli P, Pirani P, Ravetti JL, Zona G, Spaziante R, Florio T, Schettini G. Expression of the chemokine receptor CXCR4 and its ligand stromal cell-derived factor 1 in human brain tumors and their involvement in glial proliferation in vitro. Ann N Y Acad Sci. 2002; 973:60-69.
42. Li C, Li Y, Gao Y, Wei N, Zhao X, Wang C, Li Y, Xiu X, Cui J. Direct comparison of two albumin-based paclitaxelloaded nanoparticle formulations: is the crosslinked version more advantageous? Int J Pharm. 2014; 468:15-25.

43. Aslakson CJ, Miller FR. Selective events in the metastatic process defined by analysis of the sequential dissemination of subpopulations of a mouse mammary tumor. Cancer Res. 1992; 52:1399-1405.

44. Mi Z, Guo H, Wai PY, Gao C, Wei J, Kuo PC. Differential osteopontin expression in phenotypically distinct subclones of murine breast cancer cells mediates metastatic behavior. J Biol Chem. 2004; 279:46659-46667.

45. Wang L, Ling Y, Chen Y, Li CL, Feng F, You QD, Lu N, Guo QL. Flavonoid baicalein suppresses adhesion, migration and invasion of MDA-MB-231 human breast cancer cells. Cancer Lett. 2010; 297:42-48.

46. Chen J, Thompson LU. Lignans and tamoxifen, alone or in combination, reduce human breast cancer cell adhesion, invasion and migration in vitro. Breast Cancer Res Treat. 2003; 80:163-170.

47. Rodriguez LG, Wu X, Guan JL. Wound-healing assay. Methods Mol Biol. 2005; 294:23-29. 